\title{
Correction to: Heterogeneous demand for ecologically sustainable products on ensuring environmental sustainability in South Africa
}

\section{Enoch Owusu-Sekyere ${ }^{1,2} \cdot$ Awudu Abdulai $^{3} \cdot$ Henry Jordaan ${ }^{1}$}

Published online: 15 June 2019

(c) Society for Environmental Economics and Policy Studies and Springer Japan KK, part of Springer Nature 2019

\section{Correction to: Environmental Economics and Policy Studies https://doi.org/10.1007/s10018-019-00246-6}

In the original publication of the article, the author "Helena Hansson" was included inadvertently. The correct author group is published in this correction.

Publisher's Note Springer Nature remains neutral with regard to jurisdictional claims in published maps and institutional affiliations.

The original article can be found online at https://doi.org/10.1007/s10018-019-00246-6.

Enoch Owusu-Sekyere

kofiwusu23@gmail.com; enoch.owusu.sekyere@slu.se

Awudu Abdulai

aabdula@food-econ.uni-kiel.de

Henry Jordaan

JordaanH@ufs.ac.za

1 Department of Agricultural Economics, University of the Free State, Bloemfontein 9300, South Africa

2 Department of Economics, Swedish University of Agricultural Sciences, Uppsala, Sweden

3 Department of Food Economics and Consumption Studies, University of Kiel, 24098 Kiel, Germany 